\title{
Effects of Barley Yellow Dwarf Virus on Root and Shoot Growth of Winter Wheat Seedlings Grown in Aeroponic Culture
}

\author{
T. K. Hoffman and F. L. Kolb, Department of Crop Sciences, University of Illinois, Urbana 61801
}

\begin{abstract}
Hoffman, T. K., and Kolb, F. L. 1997. Effects of barley yellow dwarf virus on root and shoot growth of winter wheat seedlings grown in aeroponic culture. Plant Dis. 81:497-500.

Seedlings of eight soft red winter wheat (Triticum aestivum) cultivars were grown in an aeroponic mist box to study the effects of barley yellow dwarf virus (BYDV) on root and shoot growth and to look for differences in root and shoot growth among cultivars. The cultivars selected for the study were Caldwell, Cardinal, Clark, Howell, IL 87-2834, Tyler, and Pioneer brands 2548 and 2555. A split-plot treatment design was used, with uninfected and inoculated treatments as whole plots and cultivars as subplots. Differences among cultivars were found for most growth characteristics under both control and BYDV-infected conditions. There was a strong positive correlation between shoot and root dry weights in both the control and BYDV treatments, indicating that cultivars with vigorous shoot growth tended to have more vigorous root growth. BYDV severely reduced root length, distance from seminal root tip to the nearest lateral root, and the root to shoot ratio for all cultivars tested. The number of adventitious roots and shoot percent dry matter were increased by BYDV infection for some cultivars. Chlorosis and stunting were not observed in shoots during the 18 days of the experiment, whereas roots were visibly stunted approximately 4 days after inoculation. Results indicate that, initially, the root system is affected more severely than the shoot in BYDV-infected wheat seedlings.
\end{abstract}

Barley yellow dwarf virus (BYDV) is one of the most economically important viruses causing diseases of small grain crops. Although disease severity varies from year to year, the virus is found in all small grainproducing regions of North America (9) as well as in many other parts of the world. The effects of BYDV on aboveground plant growth in small grain crops such as barley (Hordeum vulgare), wheat (Triticum aestivum L.), and oat (Avena sativa) have been studied extensively. Relatively little research, however, has addressed how the virus affects root growth. The few studies that have been conducted indicate that the effects of the virus on root growth are severe and more rapid than the effects of the virus on shoot growth $(7,8)$. Kainz (7) studied the dwarfing effect of BYDV on root growth and found that dwarfing of the root system usually preceded the appearance of visual symptoms in the shoot by 7 to 10 days in cultivars of barley, wheat, and oat. Dwarfing appeared to be expressed as a reduction in the length of the root system rather than a reduction in the number of roots. Root number was reduced in only one wheat cultivar.

Corresponding author: F. L. Kolb
E-mail: f-kolb@uiuc.edu

Accepted for publication 30 January 1997.

Publication no. D-1997-0304-05R

(C) 1997 The American Phytopathological Society
In another study, root elongation ceased earlier in a sensitive oat cultivar than in two less sensitive cultivars (8). In the sensitive cultivar, the root to shoot ratio decreased with infection, showing that root growth was more severely affected than shoot growth. The less sensitive cultivars did not exhibit the same decrease in the root to shoot ratio.

Because roots play a key role in plant development by providing the growing plant with water and nutrients from the soil, the reduction in water and nutrient uptake due to root stunting itself may be an important factor contributing to the reduction in shoot growth and grain yield suffered by BYDVinfected plants. There is an interrelationship between root and shoot growth, so if one is adversely affected by some factor, the effect will be greatest in that part, but eventually there will be an adjustment in the growth of the other part (11).

Genetic variability in root size among cultivars may explain partially the genotype by environment interaction for BYDV symptom severity that is well documented in small grain crops, especially wheat. For example, a genotype with a smaller root phenotype may be more severely affected by BYDV during a dry season than a genotype with a larger or deeper root system.

Although few studies have investigated the relationship between root growth and tolerance to BYDV, this relationship has been alluded to in the literature. Comeau and Jedlinski (2) suggested that the rapid rooting nature of barley may explain why barley cultivars carrying the $Y d 2$ gene are more tolerant or resistant to BYDV than wheat. The large, fast-growing root systems of rye (Secale cereale) and triticale $(\times$ Triticosecale) may explain why these species exhibit a high level of tolerance to BYDV (2). Similarly, fall-sown wheat may be more tolerant to BYDV than spring-sown wheat because it has a deeper root system (2).

Variability in rooting pattern has been found among modern wheat cultivars (4). Mian et al. (12) studied root and shoot growth characteristics of 40 soft red winter wheat cultivars in hydroponic culture and found differences in root fresh weight, number of roots longer than $40 \mathrm{~cm}$, longest root length, and total root length. Root and shoot growth of selected cultivars from the hydroponic study were correlated to root and shoot growth in the field when adequate soil moisture was present but not under drought conditions (13). In contrast Lupton et al. (10) found little evidence of differences in root growth between semidwarf and tall wheat cultivars. Some differences were reported by Lupton and coworkers, but genotypic differences were much smaller than those caused by environmental factors such as weather and soil.

The purpose of this study was to evaluate the effects of BYDV on root and shoot growth of eight soft red winter wheat cultivars and to test the hypothesis that cultivars differ in root growth characteristics under BYDV-infection. These differences may provide a basis for understanding the genotype by environment interaction observed in BYDV symptom expression and may suggest selection criteria that may lead to the development of more tolerant lines.

\section{MATERIALS AND METHODS}

The eight soft red winter wheat cultivars included in the experiment were selected based on root growth characteristics observed in a hydroponic study (12) and their adaptation to local growing conditions. In the hydroponic study, cvs. Cardinal, Howell, Pioneer brand 2555, and Tyler were characterized as large rooted, cv. Caldwell as small rooted, and cv. Clark was intermediate in root growth. IL 87-2834 (a University of Illinois experimental line) and Pioneer brand 2548 were included as high-yield, well-adapted cultivars.

The experiment was conducted in a greenhouse equipped with $1,000-\mathrm{W}$ metal halide lamps that extended day length to $16 \mathrm{~h}$. Plants were grown in an aeroponic mist box that held plants approximately $1.3 \mathrm{~m}$ from the lamps. Lamp irradiance at plant level was approximately $53 \mathrm{~W} \mathrm{~m}^{-2}$. During 
daylight hours, total irradiance was approximately $105 \mathrm{~W} \mathrm{~m}^{-2}$. Greenhouse temperatures ranged from 16 to $27^{\circ} \mathrm{C}$. Roots reached the bottom of the box 17 to 18 days after planting, at which time the samples were harvested and measurements were recorded. Eight atomizing nozzles were spaced evenly inside the box to provide a uniform misting atmosphere. A half-strength Hoagland's solution was placed in pressurized tanks connected by tubes to the atomizing nozzles in the mist box. A timer (ChronTrol model CD-4, Lindburg Enterprises, San Diego, CA) regulated a solenoid valve, and roots were misted for $1 \mathrm{~s}$ every $5 \mathrm{~min}$.

The experimental design was a split-plot with four replications. BYDV-inoculated and noninoculated control were the two wholeplot treatments, and cultivars were the eight subplots. Plants in the aeroponic box were arranged in 10 rows with 10 plants per row, but only the 64 central plants were used as experimental units for the study. The plants in the outer wells provided a border.

Seeds were placed in small wells made of $3.18-\mathrm{cm}$ polyvinylchloride pipe seated in holes drilled in the lid of the aeroponic mist chamber. Each well was $2.5 \mathrm{~cm}$ deep and was covered at the bottom with a fiberglass mesh screen (six strands per centimeter). The screen gauge was large enough to allow roots to grow freely through the mesh. Initially, three to four seeds were planted, embryo side up, per well. Wells were covered to provide darkness during seed germination. The mist that collected on the mesh screen provided adequate moisture for seed germination, after which roots grew downward through the screen and into the box. After 3 days, seedlings of similar size were thinned to one per well, and each well was filled with vermiculite to support the growing plant.

Plants were inoculated with BYDV-PAV$\mathrm{IL}$ at the two-leaf stage. Inoculations were made by placing four to five viruliferous aphids (Rhopalosiphum padi) on each plant with a wet paintbrush. A preliminary study, using enzyme-linked immunosorbent assay, determined that virus infection readily occurred with this number of aphids. Noninoculated controls were maintained in an aphid-free environment. All plants were covered with clear plastic tubes to restrict aphid movement. A very fine mesh at the top of each tube provided ventilation. Aphids fed for 2 to 3 days, after which cages were removed and all plants were sprayed with $0,0-$ dimethyl $S$-[- $N$-(methylcarbamoyl) methyl] phosphorodithioate (Cygon R 400) to kill the aphids. The experiment was terminated when roots reached the bottom of the mist box 17 to 18 days after germination.

The length of the longest root, distance from the seminal root tip to the first lateral root (measured as a percentage of seminal root length), number of lateral roots within a 5-cm section (beginning with the lateral root closest to the seminal root tip), numbers of seminal and adventitious roots, root and shoot fresh weights, and number of tillers were recorded for each plant. At the end of the experiment, roots and shoots were separated for each plant, dried at $38^{\circ} \mathrm{C}$ for 7 days, and root and shoot dry weights were recorded.

The experiment was repeated four times, and an analysis of variance was carried out using PROC ANOVA of the SAS system (14). Treatment and cultivar effects were considered fixed, and trial and replication effects were considered random. Variances of pairwise mean difference were calculated, using the method described by Carmer et al. (1) for combined experiments. These were used to calculate least significant difference values to compare treatments within cultivars and cultivars within treatments. Differences among cultivars within treatments suggested root growth traits that may condition some level of tolerance to BYDV, whereas differences among treatments within cultivars indicated which

Table 1. Effects of barley yellow dwarf virus on root and shoot growth of wheat grown in an aeroponic mist box in a greenhouse for 18 days ${ }^{\mathrm{a}}$

\begin{tabular}{|c|c|c|c|c|c|c|c|c|c|c|c|}
\hline Treatment & $\begin{array}{c}\text { Root } \\
\text { dry wt. (g) }\end{array}$ & $\begin{array}{c}\text { Shoot } \\
\text { dry wt. (g) }\end{array}$ & $\begin{array}{l}\text { Root/ } \\
\text { shoot } \\
\text { ratio }\end{array}$ & $\begin{array}{c}\text { Dry } \\
\text { matter } \\
\text { roots }(\%)\end{array}$ & $\begin{array}{c}\text { Dry } \\
\text { matter } \\
\text { shoots }(\%)\end{array}$ & $\begin{array}{l}\text { Longest } \\
\text { root }(\mathbf{c m})\end{array}$ & $\begin{array}{l}\text { Tip to first } \\
\text { lateral }^{\mathbf{b}}(\%)\end{array}$ & $\begin{array}{c}\text { Lateral } \\
\text { roots }^{c}\end{array}$ & $\begin{array}{c}\text { Seminal } \\
\text { roots }\end{array}$ & $\begin{array}{l}\text { Adventitious } \\
\text { roots }\end{array}$ & Tillers \\
\hline \multicolumn{12}{|l|}{ Cv. Caldwell } \\
\hline Control & 0.065 & 0.098 & 0.674 & 8.8 & 14.3 & 51.9 & 25 & 16 & 5.3 & 3.7 & 1.4 \\
\hline Infected & 0.060 & 0.107 & 0.580 & 10.6 & 15.3 & 39.9 & 14 & 15 & 5.3 & 4.3 & 1.4 \\
\hline \multicolumn{12}{|l|}{ Cv. Cardinal } \\
\hline Control & 0.083 & 0.115 & 0.726 & 7.5 & 15.5 & 60.2 & 24 & 19 & 5.0 & 3.4 & 0.7 \\
\hline Infected & 0.086 & 0.139 & 0.627 & 7.9 & 15.9 & 47.8 & 17 & 17 & 5.0 & 4.8 & 1.0 \\
\hline \multicolumn{12}{|l|}{ Cv. Clark } \\
\hline Control & 0.082 & 0.120 & 0.702 & 8.1 & 14.5 & 53.1 & 24 & 19 & 5.0 & 3.0 & 1.1 \\
\hline Infected & 0.068 & 0.122 & 0.583 & 9.0 & 15.7 & 39.7 & 15 & 17 & 5.0 & 3.4 & 1.0 \\
\hline \multicolumn{12}{|l|}{ Cv. Howell } \\
\hline Control & 0.073 & 0.095 & 0.782 & 8.8 & 15.2 & 53.5 & 24 & 20 & 5.5 & 4.5 & 0.9 \\
\hline Infected & 0.065 & 0.110 & 0.607 & 8.8 & 16.3 & 40.9 & 15 & 20 & 5.7 & 5.7 & 1.1 \\
\hline \multicolumn{12}{|c|}{ Cv. IL 87-2834 } \\
\hline Control & 0.080 & 0.103 & 0.794 & 9.7 & 15.3 & 51.5 & 23 & 21 & 4.8 & 3.8 & 0.8 \\
\hline Infected & 0.067 & 0.108 & 0.633 & 10.2 & 16.3 & 40.6 & 15 & 18 & 5.2 & 4.0 & 0.7 \\
\hline \multicolumn{12}{|l|}{ Cv. 2548} \\
\hline Control & 0.067 & 0.091 & 0.765 & 8.5 & 15.2 & 54.3 & 25 & 18 & 5.1 & 3.3 & 1.2 \\
\hline Infected & 0.065 & 0.100 & 0.658 & 9.6 & 16.3 & 40.5 & 16 & 16 & 5.2 & 3.8 & 1.1 \\
\hline \multicolumn{12}{|l|}{ Cv. 2555} \\
\hline Control & 0.076 & 0.105 & 0.742 & 8.3 & 14.0 & 55.6 & 25 & 19 & 5.1 & 2.3 & 1.3 \\
\hline Infected & 0.066 & 0.111 & 0.610 & 8.8 & 15.2 & 40.8 & 16 & 19 & 4.9 & 3.0 & 1.0 \\
\hline \multicolumn{12}{|l|}{ Cv. Tyler } \\
\hline Control & 0.074 & 0.104 & 0.734 & 7.3 & 14.5 & 60.9 & 25 & 19 & 5.0 & 2.8 & 0.8 \\
\hline Infected & 0.066 & 0.106 & 0.634 & 9.1 & 16.0 & 44.1 & 15 & 17 & 5.0 & 3.6 & 0.8 \\
\hline $\operatorname{LSD}^{\mathrm{d}}$ & n.s. & n.s. & 0.034 & 1.3 & 0.6 & 5.2 & 2 & n.s. & n.s. & 0.9 & n.s. \\
\hline $\mathrm{LSD}^{\mathrm{e}}$ & 0.011 & 0.017 & 0.045 & n.s. & 0.5 & 5.4 & n.s. & n.s & 0.4 & 0.8 & 0.4 \\
\hline
\end{tabular}

${ }^{a}$ Values are averages from four experiments with four replications each.

${ }^{b}$ Distance from the tip of the longest seminal root to the first lateral root (1 mm or longer). Values are expressed as a percentage of the seminal root length.

${ }^{\mathrm{c}}$ Number of lateral roots $(1 \mathrm{~mm}$ or longer), beginning with the lateral root nearest the tip and counting for a distance of $5 \mathrm{~cm}$. Values are based on three trials rather than four (laterals were not counted in the first trial).

${ }^{\mathrm{d}}$ LSD for testing treatment differences within cultivars $(P=0.05)$. n.s. $=$ not significant.

${ }^{\mathrm{e}}$ LSD for testing cultivar differences within treatments $(P=0.05)$. n.s. $=$ not significant. 
cultivars are more severely affected by BYDV.

Correlation coefficients were calculated between shoot dry weight and root growth characteristics, using PROC CORR of the SAS system (15). In an attempt to eliminate the effects of environmental variation on plant size, correlation coefficients within each treatment were calculated on cultivar averages rather than on individual plant values.

\section{RESULTS AND DISCUSSION}

Variation in growth among cultivars. Variation among cultivars was observed for most root and shoot growth characteristics among control plants, suggesting that variability in root growth exists among cultivars adapted to a particular area. Variation was found for root and shoot dry weights, root to shoot ratio, percent dry matter of shoot, root length, numbers of seminal and adventitious roots, and number of tillers (Table 1). Growth differences were not as pronounced among BYDV-infected plants, but differences were still observed (Table 1).

Because selection for root characteristics in the field is impractical, it is helpful to know whether any relationships exist between aboveground shoot growth characteristics and root growth characteristics. Correlation coefficients were calculated between shoot dry weight and root growth characteristics (Table 2). Because only eight cultivars were studied, the interpretation of correlations between shoot and root growth must be treated with caution. Among the control plants, root dry weight was the only characteristic measured that was highly correlated with shoot dry weight $(R=0.84)$. Shoot dry weight also was positively correlated with root dry weight under inoculation conditions $(R=0.89)$, indicating that, even among infected plants, plants that had the greatest shoot dry weight tended to have the greatest root dry weight. This suggests the possibility of selecting for larger root systems simply by selecting for high shoot dry weight in the seedling stage.

Effects of BYDV on growth. BYDV infection did not reduce root or shoot dry weights $(P=0.05)$ in any of the cultivars tested (Table 1), but roots were visibly stunted within a few days of infection. In contrast, symptoms of stunting and chlorosis were not observed in shoots during the course of the experiment. Thus, the visible effects of the virus developed more rapidly in roots than in shoots.

Some differences in root and shoot dry weights were observed among cultivars. Root and shoot dry weights of Cardinal were greater than all other cultivars within the BYDV treatment (Table 1). Whether the more vigorous growth of Cardinal when infected results in less yield loss needs to be studied in the future.

Throughout the vegetative phase of wheat growth, the root and shoot systems act as competitive sinks (11). The root to shoot ratio, thus, is a valuable indicator of the relative strength of one sink over the other. Root to shoot ratios were decreased by infection in all cultivars, indicating that a smaller proportion of total assimilate is transported to the root system in infected plants (Table 1). The virus appeared to reduce the strength of the root system as a sink in the seedling stage. This in turn may be responsible for the increase in shoot percent dry matter observed in all cultivars, except Cardinal (Table 1). An increase in shoot percent dry matter is a well-known symptom of BYDV infection and has been attributed to an accumulation of carbohydrates in the leaves (6). Thus, as virus-induced root damage occurs, less assimilate is transported to the root system and remains in the shoot.

Differences in root to shoot ratio were observed among BYDV-infected plants. Cardinal, IL 87-2834, 2548, and Tyler exhibited higher root to shoot ratios than Caldwell and Clark, indicating that the roots of some infected plants are stronger sinks for assimilate than in other plants. It may be that the root systems of these cultivars are not as severely affected by the virus and, therefore, are stronger sinks for assimilate.

The root to shoot ratio was the only characteristic that exhibited a cultivar by treatment interaction. This interaction resulted from a greater reduction in the root to shoot ratio for some cultivars than for others. Root to shoot ratios were reduced an average of $17 \%$ by BYDV infection, but reductions were highest for Howell (22\%) and IL 872834 (20\%); these cultivars also exhibited the highest root to shoot ratios under control conditions. Because plants with a higher root to shoot ratio transport a greater proportion of assimilate to their root systems, it is possible that immediately after infection greater quantities of virus are transported to the root systems and less to the shoots in these cultivars. This may cause greater damage to the roots and result in a greater reduction in the root to shoot ratio in these cultivars. In view of these results, it is interesting that certain environmental conditions, such as high light intensity and air temperatures cooler than the soil, which condition higher root to shoot ratios (5), also condition more severe BYDV symptoms (3).

All cultivars exhibited reductions in root length (Table 1). Reductions ranged from $21 \%$ for Cardinal and IL $87-2834$ to $28 \%$ for Tyler. These results suggest that plants infected with BYDV early in their development have a shallower root system than uninfected plants. Thus, access to water and nutrients at greater depths is limited in BYDV-infected plants, which may increase the severity of BYDV symptom expression, especially during a dry year.

Cardinal exhibited the longest root length under infection conditions. Root length for Cardinal was greater than all other cultivars, except Tyler. Similar results were observed in the control treatment, in which Tyler and Cardinal exhibited the longest root length.

Lateral roots emerged closer to the root tip on BYDV-infected plants (Table 1). Lateral root position averaged $38 \%$ closer to the seminal root tip on infected plants compared to controls. It is uncertain whether this is a result of an ability to form laterals closer to the seminal root tip or simply the result of reduced elongation of the seminal root. Although laterals roots emerged closer to the tip, BYDV did not appear to affect the number of lateral roots counted within a $5-\mathrm{cm}$ section of root, beginning with the lateral closest to the root tip (Table 1).

BYDV infection also had no effect on the number of seminal roots (Table 1). Seminal root primordia are formed at seed development (11), and seminal roots had already emerged by the time the seedlings were inoculated at the two-leaf stage.

In contrast, adventitious root formation takes place throughout the tillering phase and was not completed before infection took place. Numbers of adventitious roots were increased by infection for Cardinal and Howell (Table 1), suggesting that adventitious root formation may be stimulated by BYDV infection. These roots, however, were stunted.

Differences among cultivars were observed for shoot percent dry matter, numbers of seminal and adventitious roots, and number of tillers, but among infected plants, root length was the growth characteristic most highly correlated with root dry weight $(R=0.86)$. Thus, the ability to grow longer roots under infection appeared to be the characteristic most related to greater root mass.

Over the course of this experiment, root growth was more severely affected by BYDV infection than shoot growth. Results sug-

Table 2. Correlation coefficients between shoot dry weight and root growth characteristics of eight winter wheat cultivars grown in an aeroponic mist box in a greenhouse and inoculated with barley yellow dwarf virus (BYDV) or not inoculated $^{\mathrm{a}}$

\begin{tabular}{lcc}
\hline & \multicolumn{2}{c}{ Shoot dry weight } \\
\cline { 2 - 3 } Root characteristic & $\begin{array}{c}\text { Control } \\
\text { treatment }\end{array}$ & $\begin{array}{c}\text { BYDV } \\
\text { treatment }\end{array}$ \\
\hline $\begin{array}{c}\text { Length of longest } \\
\text { root }\end{array}$ & 0.29 & 0.67 \\
& $(0.48)^{\mathrm{b}}$ & $(0.07)$ \\
Root dry weight & 0.84 & 0.89 \\
& $(0.01)$ & $(0.003)$ \\
No. of lateral roots & 0.20 & 0.05 \\
& $(0.64)$ & $(0.90)$ \\
No. of seminal & & \\
roots & -0.49 & -0.33 \\
& $(0.21)$ & $(0.43)$ \\
No. of adventi- & & \\
tious roots & -0.40 & 0.22 \\
Root/shoot ratio & $(0.33)$ & $(0.60)$ \\
& -0.41 & -0.22 \\
& $(0.32)$ & $(0.59)$ \\
\hline
\end{tabular}

a Values were calculated based on cultivar averages over four experiments.

b Values in parentheses indicate the probability of a greater $r$ value under the hypothesis that $r h o=0$. 
gest that in the initial stages of seedling infection the virus primarily reduces growth of the root system. The typical symptoms observed in the shoot may result partially from physical damage in the roots. Symptoms may be even more severe during a dry year, when stunted root growth is coupled with limited moisture.

Variability in root growth among BYDVinfected plants indicates that it may be possible to select for certain root growth characteristics that might lessen the severity of BYDV damage. A positive correlation between shoot and root growth among infected plants suggests that selecting for high shoot dry weight under BYDV infection may select for higher root mass. Future research should investigate further the relationship between root growth and tolerance to BYDV in wheat by comparing root growth and grain yield data of BYDV-inoculated plants in the field.

\section{ACKNOWLEDGMENTS}

We thank L. L. Domier and G. R. Gregerson for maintaining the virus strain and providing aphid vectors throughout the experiment.

\section{LITERATURE CITED}

1. Carmer, S. G., Nyquist, W. E., and Walker, W. M. 1989. Least significant differences for com- bined analyses of experiments with two- or three-factor treatment designs. Agron. J. 81: 665-672.

2. Comeau, A., and Jedlinski, H. 1990. Successful breeding for barley yellow dwarf resistance or tolerance: A systematic approach related to other agronomic characteristics. Pages 441451 in: World Perspectives on Barley Yellow Dwarf. P. A. Burnett, ed. CIMMYT, Mexico, D. F., Mexico.

3. D'Arcy, C. J. 1995. Symptomatology and host range of barley yellow dwarf. Pages 928 in: Barley Yellow Dwarf: 40 Years of Progress. C. J. D'Arcy and P. A. Burnett, eds. The American Phytopathological Society, St. Paul, MN.

4. Derera, N. F., Marshall, D. R., and Balaam, L. N. 1969. Genetic variability in root development in relation to drought tolerance in spring wheats. Exp. Agric. 5:327-337.

5. Devlin, R. M., and Witham, F. H. 1983. Translocation of sugars. Pages 295-315 in: Plant Physiology. 4th ed. PWS Publishers, Boston.

6. Jensen, S. G., and D'Arcy, C. J. 1995. Effects of barley yellow dwarf on host plants. Pages 55-74 in: Barley Yellow Dwarf: 40 Years of Progress. C. J. D'Arcy and P. A. Burnett, eds. The American Phytopathological Society, St. Paul, MN.

7. Kainz, M. S. 1980. Response of cereal roots grown in mist culture to barley yellow dwarf virus. M.S. dissertation. Washington State University, Pullman.

8. Kolb, F. L., Cooper, N. K., Hewings, A. D.,
Bauske, E. M., and Teyker, R. H. 1991. Effects of barley yellow dwarf virus on root growth in spring oat. Plant Dis. 75:143145.

9. Hewings, A. D., and Eastman, C. E. 1995. Epidemiology of barley yellow dwarf in North America. Pages 75-106 in: Barley Yellow Dwarf: 40 Years of Progress. C. J. D'Arcy and P. A Burnett, eds. The American Phytopathological Society, St. Paul, MN

10. Lupton, F. G. H., Oliver, R. H., Ellis, F. B., Barnes, B. T., House, K. R., Welbank, P. J., and Taylor, P. J. 1974. Root and shoot growth of semi-dwarf and taller winter wheats. Ann Appl. Biol. 77:129-144.

11. Mac Key, J. 1979. Wheat domestication as a shoot:root interrelation process. Pages 875 890 in: Proc. 5th Int. Wheat Genet. Symp. S. Ramanujam, ed. Indian Agricultural Research Institute, New Delhi.

12. Mian, M. A. R., Nafziger, E. D., Kolb, F. L., and Teyker, R. H. 1993. Root growth of wheat genotypes in hydroponic culture and in the greenhouse under different soil moisture regimes. Crop Sci. 33:283-286.

13. Mian, M. A. R., Nafziger, E. D., Kolb, F. L., and Teyker, R. H. 1994. Root size and distribution of field-grown wheat genotypes. Crop Sci. 34:810-812.

14. SAS Institute. 1988. The ANOVA procedure. Pages 125-154 in: SAS/STAT User's Guide. Release 6.03 ed. SAS Institute, Cary, NC.

15. SAS Institute. 1988. The CORR procedure. Pages 125-149 in: SAS Procedures Guide, Release 6.03 ed. SAS Institute, Cary, NC. 